Original Article

\title{
The effects of breathing exercise types on respiratory muscle activity and body function in patients with mild chronic obstructive pulmonary disease
}

\author{
Jeong-Il Kang, PT, PhD ${ }^{1)}$, Dae-Keun Jeong, PT, PhD ${ }^{1 *}$, Hyun Chol, PT, $\mathrm{PhD}^{2)}$ \\ 1) Department of Physical Therapy, Sehan University: 1113 Noksaek-ro, Samho-eup, Youngam-gun, \\ Jeonnam 526-702, Republic of Korea \\ 2) Department of Physical Therapy, Mokpo Mirae Hosipital, Republic of Korea
}

\begin{abstract}
Purpose] Fragmentary studies on characteristics of respiratory muscles are being done to increase respiratory capacity by classifying exercises into voluntary respiratory exercise which relieves symptoms and prevents COPD and exercise using breathing exercise equipment. But this study found changes on respiratory pattern through changes on the activity pattern of agonist and synergist respiratory muscles and studied what effect they can have on body function improvement. [Subjects and Methods] Fifteen subjects in experimental group I that respiratory exercise of diaphragm and 15 subjects in experimental group II that feedback respiratory exercise were randomly selected among COPD patients to find the effective intervention method for COPD patients. And intervention program was conducted for 5 weeks, three times a week, once a day and 30 minutes a session. They were measured with BODE index using respiratory muscle activity, pulmonary function, the six-minute walking test, dyspnea criteria and BMI Then the results obtained were compared and analyzed. [Results] There was a significant difference in sternocleidomastoid muscle and scalene muscle and in 6-minute walk and BODE index for body function. Thus the group performing feedback respiratory had more effective results for mild COPD patients. [Conclusion] Therefore, the improvement was significant regarding the activity of respiratory muscles synergists when breathing before doing breathing exercise. Although, it is valuable to reduce too much mobilization of respiratory muscles synergists through the proper intervention it is necessary to study body function regarding improvement of respiratory function for patients with COPD.

Key words: Breathing exercise, Chronic obstructive pulmonary disease, Respiratory muscle activity
\end{abstract}

(This article was submitted Oct. 13, 2015, and was accepted Oct. 31, 2015)

\section{INTRODUCTION}

Chronic Obstructive Pulmonary Disease (COPD) is predicted and reported as the third cause of death in 2030 by World Health Organization (WHO) and is receiving gaining attention due to the increase in elderly population, in addition to the pollution worsening all over the world. Besides, it is known that occurrence rate and death rate increases every subsequent year this way, managing respiratory diseases is very important including COPD ${ }^{1)}$.

Patients with COPD have anatomophysiological changes such as a limitation in the shape of the diaphragm and thoracic cage $^{2)}$. These make patients more seriously impaired, leading to complains about dyspnea, a symptoms caused by airway obstruction while exercising.

As a result, it causes changes of muscle mass due to decrease of momentum and the stamina and becomes the factor

*Corresponding author. Dae Keun Jeong (E-mail: dklovept@naver.com)

(C2016 The Society of Physical Therapy Science. Published by IPEC Inc.

This is an open-access article distributed under the terms of the Creative Commons Attribution Non-Commercial No Derivatives (by-nc-nd) License $<$ http://creativecommons.org/licenses/by-nc-nd/4.0/>. 
affecting respiratory muscles ${ }^{3}$. When patients with COPD breathe, the actual respiration volume is decreasing despite of the effort for respiration. This occurs because the demand for respiration is not consistent with the energy ratio supplied by respiratory muscles ${ }^{4}$. And as the disease gets worse, respiratory failure appears and other body functions are negatively influenced due to deformation of the ventilation mechanism by overuse of respiratory muscles synergists ${ }^{5)}$. If COPD occurs once, it is impossible to cure it completely. Because it causes not only damage of the respiratory machinery, but also several physical damages and affects overall life pattern and normal body function ${ }^{6}$. Thus, fragmentary studies on characteristics of respiratory muscles are being done to increase respiratory capacity by classifying exercises into voluntary respiratory exercises which improves symptoms and prevents COPD and exercise using breathing exercise equipment ${ }^{7}$. But when the studies analyzing the respiratory muscles activity changes are being done, it is necessary to pay attention to respiratory muscles activity changes before and after the respiratory exercise. This research intends to examine the effect of agonist and synergist muscles by comparing respiratory muscles activity after the patients were submitted to respiratory exercises, as well as to find out the effective intervention method by comparing the respiratory muscles pattern and its effects on body functions.

\section{Subjects}

This study was approved by Sehan University Center's bioethics Committee (IRB) (Approval number: 2014-11) in October 1, 2014 and included 30 male patients with mild COPD aged between 55 and 70, who were receiving medical treatment in a medical institution located in Jeollanamdo, South Korea from October of 2014 to December of 2014. This experiment was composed of those who didn't have major medical diseases such as ischemic heart diseases and intermittent claudications, complications which would make participation on this program impossible; those who didn't have accompanied damages such as rib fracture and congenital thoracic cage deformations; those who didn't have rapid COPD symptoms. All subjects agreed to participate in this research and understood the objective of the research (Table 1).

\section{Procedures}

As experiment designs, we selected 15 subjects for experiment group I that performed diaphragm respiration exercise and 15 subjects for experiment group II that performed feedback respiration exercise. The mediation program was done for 5 weeks, three times a week, once a day, and 30 minutes a session. Before doing the exercise, respiratory muscles activity was measured with surface electromyogramand body function was measured with BODE index using pulmonary function, 6-minute walking test, dyspnea criteria, BMI and then the result was analyzed through comparison of the data obtained before and after the exercise within the group and between groups.

Method of feedback respiration exercise consisted on the patient sitting straight and holding a handle with respiration pocket, having a mouth piece in the mouth and staring at the connector. The therapists pushed the start button of the connector. And when the patients see the orange gradation of the body reaching the "in" mark, they inhale and when it goes to "out" mark, they exhale. If there is a beeping sound with a green light when orange mark is on "in" or "out", that means normal feedback respiration exercise. Enough explanation was given to them before doing exercise so that patients understand the method of this exercise. It was conducted within the range not to happen hypocarbia during inhaling and exhaling at maximum level ${ }^{8)}$.

Method of diaphragm respiration exercise consists on the therapists' hands placing on rectus abdominis located just below front costal cartilages and then they induce patients to inhale slowly and deeply through their nose. At this time, therapists apply proper resistance to rectus abdominis of patients when rectus abdominis rises and induce them to inhale deeply, and patients relax their shoulder and maintain it realaxed during inhaling deeply. Upper chest is fixed not to be moved and only rise of abdomen is allowed ${ }^{9}$.

Surface EMG MP 100 system (Biopac, USA) 4 channels were used to measure muscle activity of respiratory muscle and sampling rate for EMG signal collection was set 1000 and frequency band filter was set 20-450 Hz. To minimize skin resistance of EMG signal, subjects' hair was removed from their skin and dead skin cells were removed using thin sandpaper. And then their skin was rubbed with alcohol cotton and was kept in clean conditions. Two surface electrodes of Ag/Agcl were

Table 1. Characteristic of subjects

\begin{tabular}{lcc}
\hline & Experimental group I $(\mathrm{n}=15)$ & Experimental groupII $(\mathrm{n}=15)$ \\
\hline Age $($ years $)$ & $65.1 \pm 4.1^{\mathrm{a}}$ & $64.7 \pm 4.4$ \\
Hight $(\mathrm{cm})$ & $166.5 \pm 3.4$ & $164.9 \pm 3.9$ \\
Weight $(\mathrm{kg})$ & $66.2 \pm 3.9$ & $64.9 \pm 4.0$ \\
$\mathrm{BMI}\left(\mathrm{kg} / \mathrm{m}^{2}\right)$ & $23.6 \pm 3.8$ & $22.8 \pm 4.3$ \\
$\mathrm{FEV}_{1}(\%)$ & $60.4 \pm 4.8$ & $59.8 \pm 3.0$ \\
$\mathrm{FEV}$ & $\mathrm{FVC}(\%)$ & $53.2 \pm 3.4$ \\
\hline${ }^{\mathrm{a}}$ Mean $\pm \mathrm{SD}$ & $50.6 \pm 3.7$ & \\
Experimental group I: diaphragm respiration exercise group \\
Experimental group II: feedback respiration exercise group
\end{tabular}


attached to belly of each muscle in a direction parallel to muscular fiber at $2 \mathrm{~cm}$ interval. Standard electrodes were attached to spine of 12th backbone and scapula spine that are protruding parts. EMG signals of right sternocleidomastoid muscle, scalene muscle, external intercostal muscle and diaphragm were collected ${ }^{10,11)}$. Signals of measured muscle were converted to root mean square (RMS) and EMG signal analysis was done using Acknowledge 3.9.1 software program (Biopac, USA). Besides, root mean square was measured for 10 times by breathing naturally after making patients sit comfortably to normalize EMG signal of subjects. Average value of RMS of eight respirations was set as RMS when doing standard motion except RMS of first and final respiration. In addition, subjects breathed at the level 30\% of maximum inhalation pressure using Threshold Inspiratory Muscle Trainer (New Jersey, USA) which is an inhalation respiration exercise equipment and RMS value was quantified $^{10)}$. Chestgraph HI-701 (Chest, Japan) was used to measure pulmonary function and it was measured in the way that patients hold the respiration machine in their mouth in a sitting position and inhale at maximum level and then exhale with all their strength. Pulmonary capacity was measured over 3 times at least and measured figure within $200 \mathrm{ml}$ or $5 \%$ in the difference between the biggest figure and the second biggest figure. 6-minute walk was used to measure distance traveled. It marked the track at $1 \mathrm{~m}$ interval in indoor space and measurers turned on the stopwatch designed to be rung 6 minutes later when subjects started to walk, and when bell rang 6 minutes later, he measured the distance calculating the intervals marked by $1 \mathrm{~m}$. BODE index is composed of 4 items which are forced expiration capacity for 1 second (FEV1\%pred), 6-minute walking distance (m), MMRC dyspnea score, BMI (BMI, kg/m). Each item was evaluated with 0-3 score and then the total score was added for measurement ${ }^{6)}$.

\section{Data analysis}

SPSS 18.0 for window was used as data processing method and Shapiro-Wilk was used to test the normality of general characteristics of subjects, activity of respiratory muscle and body function of groups. Paired t-test was used for comparison of change within the group and analysis of covariance (ANCOVA) was used in comparison of change between groups, significance level was set as $\alpha=0.05$.

\section{RESULTS}

As a result of comparing changes of experimental group I, only diaphragm showed meaningful difference in activity of respiratory muscles $(\mathrm{p}<0.05)$. And there was a meaningful difference in FEV1 and 6-minute walking in bodyfunction $(\mathrm{p}<0.05)$ (Table 2).

As a result of changes of experimental group II, there was a meaningful difference in sternocleidomastoid muscle, scalene muscle and diaphragm regarding activity of respiratory muscles. And there was a meaningful difference in FEV1, 6-minute walking and BODE index regarding bodyfunction $(\mathrm{p}<0.05)$ (Table 3$)$.

There was a meaningful difference in sternocleidomastoid muscle and scalene muscle regarding activity of respiratory muscles in change comparison between groups. And there was a meaningful difference in 6-minute walking and BODE index in bodyfunction $(\mathrm{p}<0.05)$ (Table 4$)$.

\section{DISCUSSION}

When respiratory function of patients with COPD becomes insufficient, activity of respiratory muscle synergists increases and the patients also take a more comfortable position to breathe. To set useful method for ventilation, they change their posture, which causes changes of the functions of involuntary muscles ${ }^{12)}$.

Legrand et al. ${ }^{13)}$ says muscles around the neck bone are used for mechanical advantage in case of abnormal respiration pattern of COPD patients. Especially, sternocleidomastoid and scalene muscles are more activated for high mechanical advantage when breathing and it can be interpreted as role of supporting respiratory muscles caused by mechanical problems of worsening respiration patterns. Duiverman et al. ${ }^{11)}$ found that activity of sternocleidomastoid and scalene muscles in patients with COPD increases a lot when compared to normal adults while exercising. This finding was a result of comparing muscle activity and dyspnea after a particular set of exercises performedfor 10 minutes targeting patients with COPD. This result was related to the increase of dyspnea. As Tomich et al. ${ }^{14)}$ observed, the air-centered activity of sternocleidomastoid muscle in the exercises performed is a result of its activity. The movements of chest and abdomen observed while conducting respiratory exercises with diaphragm respiration, air-center and capacity-center have identified 17 normal people. In this research, we could see that activities of sternocleidomastoid and scalene muscles decrease in the group performing feedback respiration exercise when compared to the group performing diaphragm respiratory exercise. Deep and slow inhalation, as done in feedback respiratory exercise decreases activity of sternocleidomastoid muscle. So, it is effective to inhibit overusing synergists of respiratory muscle. Chiti et al. ${ }^{15}$ ) found that activity of scalene muscle was increased in dyspnea, inhalation induction, inhalation effort and it would be useful to reduce synergist muscle activity such as scalene muscle during mechanical ventilation. Loring et al. ${ }^{2}$ ) conducted a research in which 12 healthy people performed 2 sets of 30 repetitions each with $40 \%$ of initial maximum inspiratory pressure and as a result, muscle activity of diaphragm that is agonist of the respiratory muscles was greatly increased when inhaling. Changes in muscle activity of diaphragm were shown to improve respiratory ability because of its synergy effect while these two muscles are doing inhalation. These findings and supported this research, 
Table 2. Comparison of change in respiratory muscle activity and physical function within experimental group I

\begin{tabular}{|c|c|c|c|}
\hline & & \multicolumn{2}{|c|}{ Experimental group I $(\mathrm{n}=15)$} \\
\hline & & Pre-test & Post-test' \\
\hline \multirow{4}{*}{$\%$ RMS } & SCM & $43.2 \pm 3.4^{\mathrm{a}}$ & $43.0 \pm 2.3$ \\
\hline & Scalenius & $56.0 \pm 4.7$ & $55.0 \pm 5.0$ \\
\hline & Diaphragm & $5.9 \pm 2.3$ & $7.5 \pm 1.9^{*}$ \\
\hline & External intercostalis & $15.9 \pm 1.4$ & $16.1 \pm 1.7$ \\
\hline \multirow{3}{*}{ Pysical function } & $\mathrm{FEV}_{1}$ & $60.4 \pm 4.8$ & $61.3 \pm 4.2^{*}$ \\
\hline & $6 \mathrm{MWT}$ & $360.4 \pm 17.3$ & $369.4 \pm 12.3^{* *}$ \\
\hline & BODE index & $2.5 \pm 0.5$ & $2.5 \pm 0.5$ \\
\hline
\end{tabular}

${ }^{*} \mathrm{p}<0.05,{ }^{* *} \mathrm{p}<0.001$

${ }^{\mathrm{a}}$ Mean \pm SD, 'Paired t-test

Experimental group I: diaphragm respiration exercise group

Experimental group II: feedback respiration exercise group

Table 3. Comparison of change in respiratory muscle activity and physical function within experimental group II

\begin{tabular}{llcc}
\hline & & \multicolumn{2}{c}{ Experimental group II $(\mathrm{n}=15)$} \\
\cline { 3 - 4 } & & Pre-test & Post-test' \\
\hline \multirow{3}{*}{$\%$ SCM } & $43.8 \pm 5.7^{\mathrm{a}}$ & $40.6 \pm 3.7^{*}$ \\
& Scalenius & $56.7 \pm 3.4$ & $52.8 \pm 3.5^{* *}$ \\
& Diaphragm & $5.9 \pm 2.3$ & $7.7 \pm 2.0^{*}$ \\
& External intercostalis & $15.8 \pm 1.7$ & $16.4 \pm 2.5$ \\
& FEV & $59.8 \pm 3.0$ & $62.0 \pm 2.5^{* *}$ \\
& 6MWT & $368.3 \pm 18.1$ & $379.5 \pm 13.4^{* *}$ \\
& BODE index & $2.9 \pm 0.1$ & $2.27 \pm 0.5^{* *}$ \\
\hline
\end{tabular}

${ }^{*} \mathrm{p}<0.05,{ }^{* *} \mathrm{p}<0.001$

${ }^{a}$ Mean \pm SD, 'Paired t-test

Experimental group I: diaphragm respiration exercise group

Experimental group II: feedback respiration exercise group

Table 4. comparison of change in respiratory muscle activity and physical function between experimental group I and experimental group II

\begin{tabular}{llcccc}
\hline & & \multicolumn{2}{c}{ Experimental group I $(\mathrm{n}=15)$} & \multicolumn{2}{c}{ Experimental group II $(\mathrm{n}=15)$} \\
\cline { 3 - 5 } & & Pre-test & Post-test & Pre-test & Post-test' $^{\prime}$ \\
\hline \multirow{3}{*}{$\%$ RMS } & SCM & $43.2 \pm 3.4^{\mathrm{a}}$ & $43.0 \pm 2.3$ & $43.8 \pm 5.7$ & $40.6 \pm 3.7^{*}$ \\
& Scalenius & $56.0 \pm 4.7$ & $55.0 \pm 5.0$ & $56.7 \pm 3.4$ & $52.8 \pm 3.5^{*}$ \\
& Diaphragm & $5.9 \pm 2.3$ & $7.5 \pm 1.9$ & $5.9 \pm 2.3$ & $7.7 \pm 2.0$ \\
& External intercostalis & $15.9 \pm 1.5$ & $16.1 \pm 1.7$ & $15.8 \pm 1.7$ & $16.4 \pm 2.5$ \\
& FEV & $60.4 \pm 4.8$ & $61.3 \pm 4.2$ & $59.8 \pm 3.0$ & $62.0 \pm 2.5$ \\
& 6MWT & $360.4 \pm 17.3$ & $369.4 \pm 12.3$ & $368.3 \pm 18.1$ & $379.5 \pm 13.4^{* *}$ \\
& BODE index & $2.5 \pm 0.5$ & $2.5 \pm 0.5$ & $2.9 \pm 0.1$ & $2.3 \pm 0.5^{* *}$ \\
\hline
\end{tabular}

${ }^{*} \mathrm{p}<0.05,{ }^{* *} \mathrm{p}<0.01$

${ }^{\mathrm{a} M e a n} \pm \mathrm{SD}$, 'ANCOVA

Experimental group I: diaphragm respiration exercise group

Experimental group II: feedback respiration exercise group

so He can see that increase of activity by feedback respiration exercise is effective to reduce mechanical respiratory load.

COPD makes respiration hard due to decrease of lung capacity caused by deformation of thoracic cage by mechanical dynamics. Thus, the respiratory synergists play an important role in the maintenance of pulmonary function in these patients ${ }^{16)}$. To COPD patients, body function's state forms very close relation in conducting daily routines and 6-minute walk 
and BODE index are meaningful in comparing the effect that indicates functional activity by mediation of lung ${ }^{6)}$. Alexandra et al. ${ }^{17)}$ found that level of 6-minute walking and functional activity have increased in the group that has performed mobile feedback every day for 2 weeks targeting COPD patients. And $\mathrm{Mei}^{18)}$ mediated respiration pursing up lips that can heighten the activity of respiratory synergist in daily routine movements and exercise training by session targeting 101 COPD and after this mediation, BODE index and daily routine function were improved. This research could also see that 6-minute walk and BODE index have increased significantly in group for feedback respiratory exercise in comparison to the group for diaphragm respiratory exercise. Yamaguti et al. ${ }^{9}$ mediated diaphragm respiratory exercise for a total of 45 minutes repeating 3 sets a session of 10 repetitions each, three times a week for 4 weeks targeting 30 patients with COPD and there was a meaningful difference in 6-minutes walking test and motility of diaphragm 4 weeks later. But there was no meaningful difference in BODE index and this fact supported this research. The reason is that respiratory muscle exercise can obtain inhalation flow or inhalation pressure set as aims using resistant respiration during training for improvements of respiratory function ${ }^{19)}$. Especially feedback respiratory exercise helps to improve endurance and strength of muscle by applying load to inhalation synergist and diaphragm ${ }^{20)}$. So, feedback respiratory exercise mobilizing respiratory synergist when compared to respiratory exercise of diaphragm is considered to help to improve body function. Watz et al. ${ }^{21)}$ say that another problem of COPD which is not researched is the difference between different physical activities at severe stage of COPD. Although symptoms are weak, it is difficult to recover after there was a lung damage and the progress of symptoms can change the functional pattern of life with structural problems, it implies importance of breathing exercise before reaching severe levels of damage.

This research found that of respiratory muscles synergists activities in patients with mild COPD decreased because deformed thoracic cage and contraction of peripheral muscles were solved by mechanical advantage and it worked as a necessary factor for maintenance of respiratory function. It was possible to see the significant improvement in activity of synergists of respiratory muscles when breathing before doing breathing exercises, but it is valuable to reduce too much mobilization respiratory muscles synergists through the proper intervention. It is considered that it is necessary to study body function for the improvement of respiratory function for patients with COPD.

\section{ACKNOWLEDGEMENT}

This paper was supported by the Sehan University Research Fund in 2016.

\section{REFERENCES}

1) WHO: Chronic obstructive pulmonary disease (COPD). The global burden of disease: 2004 update. World Hearlth Organization, 2008.

2) Jung JH, Shim JM, Kwon HY, et al.: Effects of abdominal stimulation during inspiratory muscle training on respiratory function of chronic stroke patients. J Phys Ther Sci, 2014, 26: 73-76. [Medline] [CrossRef]

3) Marquis K, Debigaré R, Lacasse Y, et al.: Midthigh muscle cross-sectional area is a better predictor of mortality than body mass index in patients with chronic obstructive pulmonary disease. Am J Respir Crit Care Med, 2002, 166: 809-813. [Medline] [CrossRef]

4) Ottenheijm CA, Jenniskens GJ, Geraedts MC, et al.: Diaphragm dysfunction in chronic obstructive pulmonary disease: a role for heparan sulphate? Eur Respir J, 2007, 30: 80-89. [Medline] [CrossRef]

5) Shingai K, Kanezaki M: Effect of dyspnea induced by breath-holding on maximal muscular strength of patients with COPD. J Phys Ther Sci, 2014, 26: 255-258. [Medline] [CrossRef]

6) Kido S, Nakajima Y, Miyasaka T, et al.: Effects of combined training with breathing resistance and sustained physical exertion to improve endurance capacity and respiratory muscle function in healthy young adults. J Phys Ther Sci, 2013, 25: 605-610. [Medline] [CrossRef]

7) Moon JW, Oak JS, An KO: The effect of 12 week exercise training on cardiopulmonary and muscular function in chronic obstructed pulmonary disease patients. Korean Acadaemy Kinesiology, 2013, 15: 97-108. [CrossRef]

8) Han JM, Kim HA, Koo JP, et al.: Effects of respiratory muscle activity in stroke patients after feedback breathing exercise. J Int Acad Phys Ther Res, 2013, 4: 552-556. [CrossRef]

9) Yamaguti WP, Claudino RC, Neto AP, et al.: Diaphragmatic breathing training program improves abdominal motion during natural breathing in patients with chronic obstructive pulmonary disease: a randomized controlled trial. Arch Phys Med Rehabil, 2012, 93: 571-577. [Medline] [CrossRef]

10) Hawkes EZ, Nowicky AV, McConnell AK: Diaphragm and intercostal surface EMG and muscle performance after acute inspiratory muscle loading. Respir Physiol Neurobiol, 2007, 155: 213-219. [Medline] [CrossRef] 
11) Duiverman ML, de Boer EW, van Eykern LA, et al.: Respiratory muscle activity and dyspnea during exercise in chronic obstructive pulmonary disease. Respir Physiol Neurobiol, 2009, 167: 195-200. [Medline] [CrossRef]

12) McKenzie DK, Butler JE, Gandevia SC, et al.: Respiratory muscle function and activation in chronic obstructive pulmonary disease. J Appl Physiol 1985, 2009, 107: 621-629. [Medline] [CrossRef]

13) LeGrand SB, Khawam EA, Walsh D, et al.: Opioids, respiratory function, and dyspnea. Am J Hosp Palliat Care, 2003, 20: 57-61. [Medline] [CrossRef]

14) Tomich GM, França DC, Diório AC, et al.: Breathing pattern, thoracoabdominal motion and muscular activity during three breathing exercises. Braz J Med Biol Res, 2007, 40: 1409-1417. [Medline] [CrossRef]

15) Chiti L, Biondi G, Morelot-Panzini C, et al.: Scalene muscle activity during progressive inspiratory loading under pressure support ventilation in normal humans. Respir Physiol Neurobiol, 2008, 164: 441-448. [Medline] [CrossRef]

16) Coutinho Myrrha MA, Vieira DS, Moraes KS, et al.: Chest wall volumes during inspiratory loaded breathing in COPD patients. Respir Physiol Neurobiol, 2013, 188: 15-20. [Medline] [CrossRef]

17) Wewel AR, Gellermann I, Schwertfeger I, et al.: Intervention by phone calls raises domiciliary activity and exercise capacity in patients with severe COPD. Respir Med, 2008, 102: 20-26. [Medline] [CrossRef]

18) He M, Yu S, Wang L, et al.: Efficiency and safety of pulmonary rehabilitation in acute exacerbation of chronic obstructive pulmonary disease. Med Sci Monit, 2015, 21: 806-812. [Medline] [CrossRef]

19) Scherer TA, Spengler CM, Owassapian D, et al.: Respiratory muscle endurance training in chronic obstructive pulmonary disease: impact on exercise capacity, dyspnea, and quality of life. Am J Respir Crit Care Med, 2000, 162: 1709-1714. [Medline] [CrossRef]

20) Moodie L, Reeve J, Elkins M: Inspiratory muscle training increases inspiratory muscle strength in patients weaning from mechanical ventilation: a systematic review. J Physiother, 2011, 57: 213-221. [Medline] [CrossRef]

21) Watz H, Waschki B, Meyer T, et al.: Physical activity in patients with COPD. Eur Respir J, 2009, 33: 262-272. [Medline] [CrossRef] 